\title{
A systematic review of online depression screening tools for use in the South African context
}

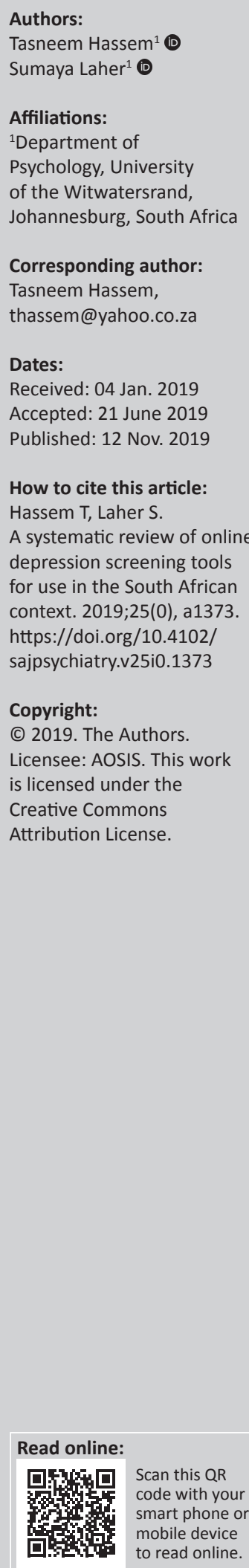

Background: According to the World Health Organization, the alarming increase in rates of depression globally has become a serious concern. In 2010, the prevalence rate of depression in South Africa was $4.6 \%$. Given the context of South Africa where the majority of the population have limited access to healthcare facilities and $59.3 \%$ of the population have access to the Internet, an online depression screening tool would have much to offer.

Objective: To determine whether online depression screening tools would be suitable for use in South Africa.

Methods: This study presents a systematic review of online depression screening tools to determine whether one would be suitable for use in South Africa. Articles were accessed from seven electronic databases from 1970 to 2018. All articles included in the review were critically appraised.

Results: A total of 17 articles met the inclusion criteria. From the results, there was only one screening tool available on an open access platform for use by the general population. The most common depression online screening tools were the Beck Depression Inventory-II (BDI-II), the Center for Epidemiology Studies Depression Scale (CES-D) and the Patient Health Questionnaire (PHQ-9). It was also evident that there were negligible differences in the psychometric properties of online versus paper versions of the online screening tools. Furthermore, there were very few studies that considered the African or South African population and no online screening tools for major depressive disorder (MDD) developed in these contexts.

Conclusion: There appears to be a need for a depression screening tool to be adapted for online usage in South Africa. It is recommended that the online screening tool should be adapted from the three commonly used online depression screening tools: PHQ-9, CES-D and BDI-II.

Keywords: BDI-II; CES-D; depression; major depressive disorder; PHQ-9; screening tool.

\section{Introduction}

A worldwide increase in depression prevalence rates by more than 18\% from 2005 to 2015 has listed depression as a leading cause of disability and ill health. ${ }^{1}$ According to the global burden of disease study in 2010, 5.0\% of the southern sub-Saharan African population was diagnosed as having major depressive disorder (MDD) ${ }^{2}$ In South Africa, the MDD prevalence rate in 2010 was $4.6 \%{ }^{2}$ The majority of depression screenings are first made in primary care facilities, where accurate diagnoses of depression in patients only occur in less than $50.0 \%$ of cases. ${ }^{3}$ This inaccuracy is often attributed to the lack of resources available in these facilities, time constraints, lack of training as well as screening tool bias. ${ }^{4}$ Primary healthcare providers often want to use screening tools that require the least amount of training and time to administer and interpret. ${ }^{5}$

The majority of the paper-based depression screening tools are based on the Diagnostic and Statistical Manual of Mental Disorders (DSM), 4th Edition (DSM-IV) or DSM, 4th Edition, Text Revision (DSMIV-TR) classification of MDD.,6 This classification was revised in the DSM 5th Edition (DSM 5), where the categories of a single and recurrent depressive episode, as well as the symptoms of bereavement, were removed. Furthermore, the DSM criteria for depression are often criticised for being based on a Western set of cultural assumptions. These assumptions include the autonomy and uniqueness of each individual, the focus on the intrapersonal rather than interpersonal symptoms and the emphasis on emotional symptoms as a classification for depression. These Western cultural norms are not universal as various cultures view individuals as being interdependent; and the mind and body are not viewed as distinct entities but rather as mutually constitutive. ${ }^{8}$ The DSM classification is based on a dichotomous approach when it comes to MDD diagnoses, but this approach is unclear. As a result, depression can either be overdiagnosed or underdiagnosed and depression diagnostic tools should be utilised with extreme caution in non-Western-based societies.

Note: The terms 'major depressive disorder' and 'depression' are used interchangeably in the literature. However, the researchers have ensured that research cited and used is focussed on MDD even if the term 'depression' is used in the study. 
Hence, the applicability of the tools designed using these criteria must be explored. ${ }^{3}$ Illness presentation in African cultures is bound to traditional religious beliefs, social relations as well as cosmology. ${ }^{9}$ While spirituality and culture are relevant across the diverse spectrum of the South African population, screening tools for depression have not been adapted to account for these unique cultural and spiritual presentations of depression.

South African research on MDD screening has considered the paper versions of the Patient Health Questionnaire 9 (PHQ-9), Center for Epidemiological Studies Depression Scale (CES-D) and Beck Depression Inventory II (BDI-II). ${ }^{10,11,12,13}$ Smit et al. ${ }^{10}$ reported lower sensitivity and specificity scores for the South African HIV-positive sample when compared to the pooled analysis for the CES-D. Kagee et al. ${ }^{11}$ found that the BDI-II was a reliable screening tool amongst HIV-positive patients in South Africa. Baron et al. ${ }^{12}$ used the isiZulu, isiXhosa and Afrikaans versions of the 10 item CES-D (CES-D 10) with a sample from the general population and reported a sensitivity of $71.4 \%$, with $72.6 \%$ of individuals in the sample being correctly identified.

Makhubela et al. ${ }^{13}$ reported good reliability as well as good convergent and discriminant validity for the BDI-II in the general population. There have been no studies considering the online screening of MDD in South Africa.

Using the Internet to screen for a psychological disorder is becoming more common. With the increasing growth in Internet usage, it has become the first source for individuals to search for information. ${ }^{14}$ Information found on the Internet with regard to medical conditions is often updated with expert information, making it the largest medical library worldwide. ${ }^{15}$ The benefits of accessing medical information include the convenience, expert information that is accessed at little or no cost and privacy. Stigma against mental illness is still very prevalent in societies where people with depression are viewed as undesirable to be around as they are seen to be responsible for their own condition. Individuals fear to seek professional help because of the response they will get from community members. ${ }^{16}$ The Internet offers protection from such stigma.

While there are multiple benefits of using the Internet, the wealth of information is often overwhelming for many. Morahan-Martin ${ }^{15}$ conducted a Google search using the phrase 'mental disorder test'. The results indicated 244000 pages were available. The researcher's personal search for this study using the phrase 'depression screening tool' yielded 170000 pages of information on a Google search. These numbers suggest that there is a great demand for such tests by the general public. According to the General Household Survey 2016, 59.3\% of households in South Africa had at least one member who had access to the Internet and $53.9 \%$ of South Africans had mobile Internet access. ${ }^{17}$ These figures suggest the possibility of online screening tools providing access to information in South Africa where mental health resources are limited and often inaccessible. ${ }^{18}$
In a scoping review and evaluation of 32 web-based intervention programmes for depression, ${ }^{19}$ the authors found that the majority of the programmes targeted an adult population $(n=19)$, while only two studies had a specific target population. Users of these programmes were required to complete a depression assessment either prior to registration, independent of the programme or during the programme, where results were received immediately upon completion. Of the 32 programmes, the authors report only 17 programmes to have used a validated depression screening tool such as the PHQ-9, BDI or the CES-D. However, it has not been stated if these tools were validated for online usage.

Concerns have been raised with regard to the effectiveness of online tests. ${ }^{20}$ Buchanan asserts that the psychometric properties of online tests differ when compared to pencil and paper versions of the test; therefore, these properties must be considered, despite the online version of the test being a direct translation of the pen-and-paper instrument. ${ }^{20}$ Very few of the psychological tests available were developed by professionals in the field therefore do not have established psychometric properties. ${ }^{20}$

Therefore, this study used the method of systematic review to establish if there were any appropriate online depression screening tools for use in the South African context. Hence, the specific questions for this study were:

- Which MDD screening tools are available online?

- What are the psychometric properties of these screening tools?

- Have any of these screening tools been used in the South African context?

- Which tool(s) can be adapted for the South African population if none have been used or adapted before?

\section{Methods \\ Research design}

A qualitative systematic review was the chosen method for this study, as a qualitative analysis was conducted on both quantitative and qualitative studies, which were included in this study. ${ }^{21}$ The eight-stage procedure for conducting systematic reviews recommended by Uman ${ }^{22}$ was followed. Stages 1-4 required the researcher to formulate the review questions, define inclusion and exclusion criteria, and develop a search strategy and, lastly, to select studies. During stages 5 and 6 , the researcher needed to extract the data from included studies and critically appraise the included studies. Finally, during stages 7 and 8 , the researcher was required to analyse and interpret the extracted data and disseminate the findings.

\section{Search process}

The steps outlined in the Preferred Reporting Items for Systematic Reviews and Meta-Analyses (PRISMA) statement were followed for data collection..$^{23}$ Articles were accessed from the Academic Search Complete, EBSCO Host: Psychology and Behavioural Science Collection, Sabinet, 
Academic Search Premier, PsychInfo, ProQuest Psychology journals and the PubMed electronic databases. These databases were selected as they provide international and African-focused multi- and interdisciplinary scholarly literature. Reference lists of selected articles were screened for any additional eligible articles. The following keywords were used: 'online depression screening tools', 'Internet depression screening tools', 'using the Internet to screen for depression', 'web-based depression screening tools', 'web-based depression assessments', 'screening for depression on the Internet' as well as 'depression assessments on the Internet'. All articles' search results were saved to Zotero (a referencing software). Articles were screened using three phases: title screening, abstract screening and full-text screening. Article titles and abstracts were screened by the first author as well as an independent researcher.

\section{Study eligibility}

To be included in the sample, the following inclusion criteria were used: (1) articles needed to be written in English; (2) only articles published from 1970 to 2017 were considered as the first large-scale online testing and interpretation of psychological assessments occurred in the early 1970s; ${ }^{24}$ (3) the study must be conducted on adults from the general public (18 years and above); (4) the study must contain a description of the MDD screening instrument that must have been specifically designed or adapted for an online environment. Articles were excluded if the screening tool was used on patient (including medical and psychiatric) samples as this study focused on reviewing articles on a screening tool that could be used on the general population, not on those already diagnosed with MDD. Articles where the depression screening instrument was combined with another screening instrument were also excluded as psychometric properties reported were unclear for subscales of the tools. Grey literature was also excluded from the search as the authors deemed peer-reviewed research to be more rigorous.

\section{Data analysis, extraction and quality assessment}

Data was analysed using content analysis, which proceeded in three phases. ${ }^{25}$ In the first phase units of analysis were selected, such as the instruments description section, sample section and the results section where instruments were validated. The second phase used an inductive approach where data was organised in terms of free coding, creating categories and abstraction. Lastly, data was reported in terms of the codes determined in phase 2. Included articles were assessed using the criteria proposed in the Critical Appraisal Skills Programme (CASP). ${ }^{26}$ Quantitative studies were scored out of 11 points, where a score between 11-8 was considered strong, 7-4 was considered moderate and 3-0 was considered weak. All studies received a score of 9,10 or 11 , with the exception of the study by Harvey et al..$^{27}$ This qualitative study received a score of 5 out of 6 , which represented a strong appraisal score $^{28}$ (see Table 1).

\section{Ethical consideration}

Articles obtained for analysis in the review were all available in the public domain; as a result no special ethical considerations were required.

\section{Results}

Through the various database searches and additional reference list searches, a total of 4777 articles were identified. After removing duplicates, 2957 article titles were screened. The total number of articles excluded based on titles and abstracts amounted to 2748 and 187, respectively. Seventeen articles were identified for possible inclusion in the study. As such, all 17 articles were used for the review (see Figure 1).

\section{Description of included articles}

Table 1 provides a brief descriptive overview of the articles. Of the 17 studies, 5 articles looked at the association of depression and another psychological measure, 4 articles assessed the psychometric properties of an online screening tool for depression, 3 articles made a direct comparison of a paper versus Internet version of a depression screening tool, ${ }^{29,30,31} 3$ articles were a feasibility study of an intervention that utilised a depression screening tool, ${ }^{32,33} 1$ article was based on an intervention study and 1 article was a qualitative descriptive article. The qualitative descriptive article obtained data on the experience of an online depression screening tool from general practitioners. ${ }^{33}$

Sample sizes obtained in each study ranged from 87 to 24965 individuals, with the exception of the qualitative study. The qualitative study conducted by Krog et al. ${ }^{28}$ interviewed nine general practitioners. The majority of the participants in the study samples were women, ${ }^{15}$ with the exception of the studies conducted by Krog et al., ${ }^{28}$ Lee et al. ${ }^{34}$ and $\mathrm{Du}$ et al. ${ }^{35}$ All study samples included participants over the age of 18 years, with an age range between 18 and 92 years. Samples recruited in the studies were representative of very specific target populations, with the majority of the studies recruiting US citizens. The only study open to a global sample was that by Leykin et al., ${ }^{36}$ where anyone who had access to the Internet could participate. Of the sample obtained for a follow-up screening, the following countries were represented: the United Kingdom, India and South Africa $(n=150)$. No other studies were conducted in Africa or South Africa.

\section{Tools available online}

The following screening tools were used in the studies: PHQ-9, CES-D, BDI-II, Edinburgh Depression Scale (EDS), Single Item Depression (SID) Scale (Dutch version), electronic Major Depressive Inventory (eMDI) (Dutch version), Major Depressive Episode (MDE) Screener, Internet-Based SelfAssessment Program for Depression (ISP-D), Kessler Psychological Distress Scale (K10) and the self-rating version of the Montgomery Asberg Depression Rating Scale (MADRS-S) (Table 2). The PHQ-9 was utilised by the majority 


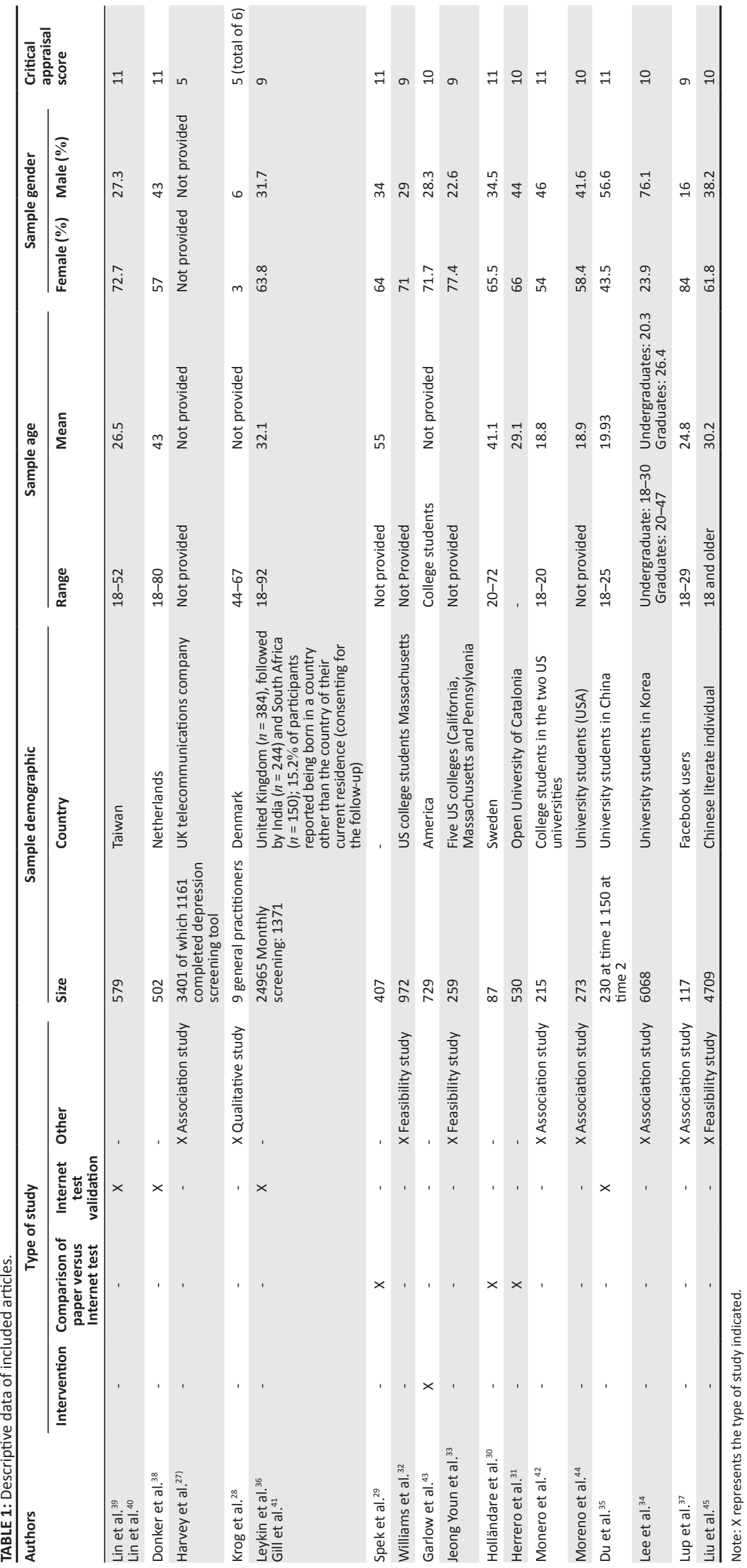




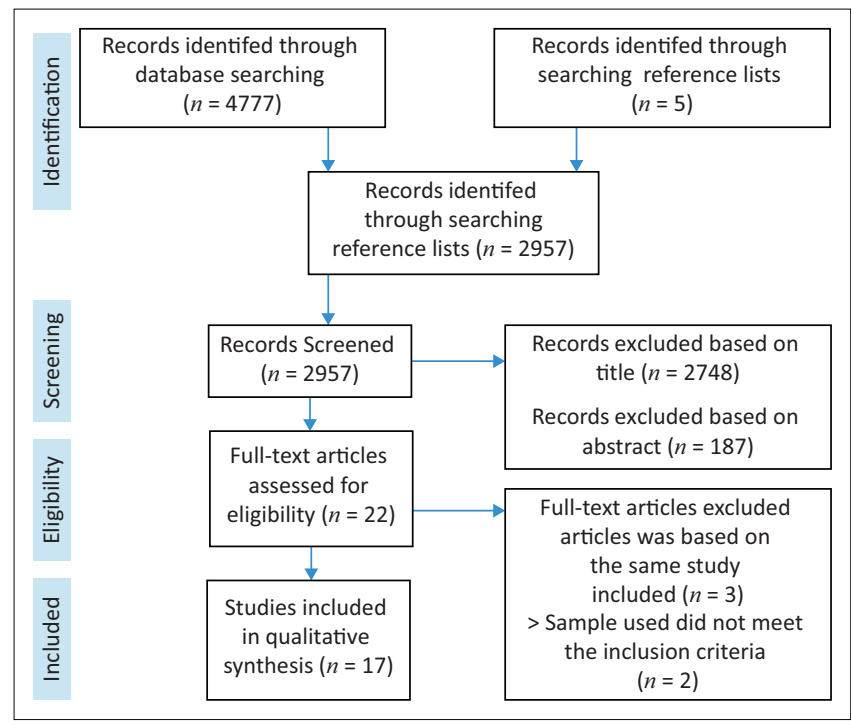

FIGURE 1: Preferred Reporting Items for Systematic Reviews and Meta-Analyses flow diagram of article inclusion and exclusion.

( $n=7)$ of studies, followed by the CES-D $(n=3)$ and BDI-II $(n=3)$. The remainder of the depression screening tools were only utilised once by their respective studies.

\section{Psychometric properties of tools}

Despite being used in the majority of studies, only one of the studies reported on the validity and reliability of the PHQ-9 tool. The study conducted by Du et al. ${ }^{35}$ utilised the Chinese version of the PHQ-9 and reported a Cronbach's alpha score of 0.8 , test-retest reliability for a 2 -week period of 0.78 and inter-item correlations of $0.54-0.69$. Three studies ${ }^{32,33,42}$ made mention of psychometric properties of the paper version of the PHQ-9 (see Table 2).

Of the three studies that utilised the CES-D, only one study did not report psychometric properties for the online version of the instrument (see Lup et al.). ${ }^{37}$ Herrero et al. ${ }^{31}$ showed that the reliability for the paper and online versions of the CES-D were virtually equal (0.83 and 0.82 , respectively). A relatively higher reliability value for the online CES-D of 0.92 was obtained by Donker et al. ${ }^{38}$ It should be noted, however, that these authors utilised the Dutch version of the CES-D. With regard to the sensitivity and specificity of the CES-D, Donker et al. ${ }^{38}$ reported a sensitivity of 0.94 and specificity of 0.62 at a cut-off of 22 . The authors highlighted a higher sensitivity and lower specificity of the online version of the CES-D when compared to the paper-based version of the tool.

Two studies utilised the BDI-II as an online depression screening tool. The study conducted by Holländare et al. ${ }^{30}$ compared the paper- and online psychometric properties of the BDI-II. The authors reported that the Cronbach's alpha levels were similar to the online version, ranging from 0.87 to 0.89 , and the paper version, ranging from 0.89 to 0.90 . The participants were required to be fluent in Swedish, therefore suggesting that the BDI-II was translated.
Lee et al. ${ }^{34}$ utilised the Korean version of the BDI-II. They did not report any online psychometric properties, but rather made reference to past studies which were paper-based psychometric properties.

Studies which utilised less common depression screening tools have reported some psychometric properties of these tools, with the exception of studies conducted by Krog et al. ${ }^{28}$, Leykin et al. ${ }^{36}$ and Liu et al. ${ }^{45}$ Lin et al. ${ }^{39}$ provided a test-retest reliability for the ISP-D of 0.83 for a 2-week period, 0.45 for a period of 2-4 weeks and, lastly, 0.50 for a period longer than 4 weeks. In addition, the authors reported a sensitivity of $76.4 \%$ and a specificity of $81.8 \%$ for 55 participants.

For the Dutch version of the SID, Donker et al. ${ }^{38}$ reported a sensitivity of 0.87 and specificity of 0.51 at a cut-off score of 5 , as well as a 0.90 reliability for the K10 and a sensitivity of $0.69-0.81$ and a specificity of $0.67-0.79$ for cut-off scores of 29, 31 and 32 for the K10. When looking at the online version reliability of the MADRS-S, Holländare et al. ${ }^{30}$ reported that the Cronbach's alpha of the online version was similar to that of the paper version.

The EDS evidenced a good internal consistency $(\alpha=0.87)$ and displayed a significant correlation when compared to the online version of the BDI-II. ${ }^{29}$

\section{Applicability for South African population}

Based on the review, there were no studies of online MDD screening tools targeting the South African population. It should be acknowledged that a small proportion of the sample in the study by Leykin et al. ${ }^{36}$ reported being South African upon follow-up assessments. Of the tools and studies identified, the majority of the tools ${ }^{13}$ were based on the DSM-IV classification of depression. The only tools that the researcher managed to locate in the South African context were two online questionnaires currently available on a non governmental organisation (NGO) website (see http://sadag.org/images/pdf/sphere_questionnaire. pdf and http://sadag.org/index.php?option=com_content \&view=article\&id=1877\&Itemid=142). The NGO uses the Somatic and Psychological Health Report (SPHERE) questionnaire and the Zung Self-Rating Depression Scale. There are no published psychometric properties for either instrument for the South African population.

\section{Discussion}

This systematic review aimed to determine if there is an appropriate online depression screening tool for use in the South African context, either in the primary healthcare sector or by the general public. Of the 17 articles included in the study, only seven articles reported psychometric properties for an online-based depression screening tool. In addition, only one article out of the 17 articles targeted a global Internet population when screening for depression. The remainder of the studies targeted very specific populations 
TABLE 2: Description of online depression screening tools.

\begin{tabular}{|c|c|c|c|c|}
\hline Authors & MDD tool used & $\begin{array}{l}\text { Depression } \\
\text { diagnosis criteria }\end{array}$ & Reliability information & Validity information \\
\hline $\begin{array}{l}\text { Lin et al. } .^{39} \\
\text { Lin et al. }{ }^{40}\end{array}$ & ISP-D & DSM-IV & $\begin{array}{l}\text { Test retest ( } 184 \text { participants): } \\
\text { - } 2 \text { weeks: } 0.830 \\
\text { - } 2-4 \text { weeks: } 0.449 \\
\text { longer than } 4 \text { weeks: } 0.499 .\end{array}$ & Sensitivity: $76.4 \%$, specificity: $81.8 \%$ (55 participants) \\
\hline Donker et al. ${ }^{38}$ & $\begin{array}{l}\text { - } \text { SID (Dutch version) } \\
\text { CES-D (Dutch } \\
\text { version) } \\
\text { - K10 (Dutch } \\
\text { version). }\end{array}$ & $\begin{array}{l}\text { CES-D: previously } \\
\text { validated depression } \\
\text { scales (BDI). }\end{array}$ & $\begin{array}{l}\text { - CES-D: } \alpha=0.92 \\
\text { K10: } \alpha=0.90 \\
\text { - SID consists of only one item. } \\
\text { Cronbach's } \alpha \text { could not be } \\
\text { calculated. }\end{array}$ & $\begin{array}{l}\text { Correlations among the three measures ranged from } 0.68 \text { of the SID with } \\
\text { the CES-D and with the K10 (both } p<0.001) \text { to } 0.84 \text { of the CES-D with the } \\
\text { K10 }(p<0.001) \\
\text { - SID: cut off score } 5 \text { : sensitivity: } 0.87 \text {; specificity: } 0.51 \\
\text { - CES-D: cut off score 22: sensitivity: } 0.94 \text {; specificity: } 0.62 \\
\text { - K10: cut-off score } 29,31,32 \text { : sensitivity: } 0.69-0.81 \text {; specificity: } 0.67-0.79\end{array}$ \\
\hline Krog et al. ${ }^{28}$ & eMDI (Dutch version) & ICD 10 & Not Provided & $\begin{array}{l}\text { No formal validity information provided. However, authors note that } \\
\text { previous experience with the MDI paper made the eMDI easier to interpret } \\
\text { and use. eMDI made process of documenting patient scores easier and } \\
\text { efficient. The time taken to login to the MDI is relatively long. }\end{array}$ \\
\hline Spek et al. ${ }^{29}$ & EDS & - & $\begin{array}{l}\text { The Internet-administered EDS has } \\
\text { a good internal consistency: } \\
\text { comparable to that of the paper } \\
\text { and pencil EDS } \alpha=0.87\end{array}$ & $\begin{array}{l}\text { The Internet-administered EDS correlated significantly with the Internet- } \\
\text { administered } \mathrm{BDI}(r=0.75 ; p<0.001) \text {. The positive predictive values were } \\
\text { comparable to those found in previous paper and pencil studies. }\end{array}$ \\
\hline Moreno et al. ${ }^{44}$ & PHQ-9 & DSM-IV & Not provided & Not provided \\
\hline Harvey et al. ${ }^{27}$ & PHQ-9 & DSM-IV & Not provided & Not provided \\
\hline Williams et al. ${ }^{32}$ & PHQ-9 & DSM-IV & Not provided & Description of the validity of the paper-based PHQ was provided \\
\hline Moreno et al. ${ }^{42}$ & PHQ-9 & DSM-IV & Not provided & $\begin{array}{l}\text { No formal validity information provided. However, authors note that the } \\
\text { tool has been previously validated. References provided were checked and } \\
\text { the validity information provided was not for the online tool }\end{array}$ \\
\hline Du et al. ${ }^{35}$ & $\begin{array}{l}\text { PHQ-9 (Chinese } \\
\text { version) }\end{array}$ & DSM-IV & $\begin{array}{l}\text { Cronbach's alpha: } 0.8 \text { two-week } \\
\text { test retest: } 0.78 \text { item correlations: } \\
0.54-0.69\end{array}$ & $\begin{array}{l}\text { Cut-off score of greater than or equal to } 10 \text { sensitivity: } 0.74 \text { and } \\
\text { specificity }=0.85 \\
\text { Likelihood ratio of } 5.08 \text {. No major difficulties in the administration. Students } \\
\text { were satisfied with the scale; however, on the satisfaction rating } \\
\text { comprehension was judged negatively }\end{array}$ \\
\hline Garlow et al. ${ }^{43}$ & PHQ-9 & DSM-IV & Not provided & Not provided \\
\hline $\begin{array}{l}\text { Jeong Youn } \\
\text { et al. }{ }^{33}\end{array}$ & PHQ-9 & DSM-IV & $\begin{array}{l}\text { Provide reference to the paper } \\
\text { version psychometrics. }\end{array}$ & Provide reference to the paper version psychometrics. \\
\hline $\begin{array}{l}\text { Holländare } \\
\text { et al. }{ }^{30}\end{array}$ & MADRS-S \& BDI & $\begin{array}{l}\text { - BDI: DSM-IV } \\
\text { MADRS-S: } \\
\text { Comprehensive } \\
\text { Psychopathological } \\
\text { rating scale (1979 } \\
\text { scale was } \\
\text { developed) }\end{array}$ & $\begin{array}{l}\text { - Cronbach's alpha levels for the } \\
\text { MADRS-S for the online version } \\
\text { of the test ranged from } 0.73 \text { to } \\
0.81 \text { and the paper version was } \\
0.81 \text {. } \\
\text { - For the BDI-II, Cronbach's alpha } \\
\text { levels for the online version of } \\
\text { the test ranged between } 0.87 \\
\text { and } 0.89 \text { and the paper version } \\
\text { was between } 0.89 \text { and } 0.90 \text {. }\end{array}$ & $\begin{array}{l}\text { - Correlations between the Internet and paper versions of all MADRS-S } \\
\text { items were significant. ( } r=0.84 \text { and } 0.79 \text { for suicide item) } \\
\text { - Correlation between the BDI-II total scores from the Internet } \\
\text { administration and the paper administration was high, } r=0.89 \text { and } 0.80 \\
\text { for the suicidal item. }\end{array}$ \\
\hline Herrero et al. ${ }^{31}$ & CES-D & $\begin{array}{l}\text { Previously validated } \\
\text { tests (BDI) }\end{array}$ & $\begin{array}{l}\text { CES-D (seven items) } \\
\text { Scale virtually equalled as for both } \\
\text { conditions; Internet } \alpha=0.82 \text { and } \\
\text { paper } \alpha=0.83 \text {. }\end{array}$ & $\begin{array}{l}\text { Confirmatory factor analysis showed that both the Internet and paper } \\
\text { version of the CES-D loaded in a single factor. }\end{array}$ \\
\hline Lup et al. ${ }^{37}$ & CES-D & $\begin{array}{l}\text { Previously validated } \\
\text { tests (BDI) }\end{array}$ & Report paper-based properties. & Report paper-based properties. \\
\hline Liu et al. ${ }^{45}$ & MDE (Chinese version) & - & Report paper-based properties. & Report paper-based properties. \\
\hline
\end{tabular}

ISP-D, Internet-Based Self-Assessment Program for Depression; CES-D, Center for Epidemiology Studies Depression; BDI, Beck Depression Inventory; DSM, Diagnostic and Statistical Manual; DSM-IV, Diagnostic and Statistical Manual of Mental Disorders, 4th Edition; PHQ, Patient Health Questionnaire; SID, Single Item Depression; MDE, major depressive episode.

(college students, primary care patients as well as individuals diagnosed with depression).

The most commonly used online depression screening tools were the PHQ-9, CES-D and BDI-II. These results are in accordance with the most common paper-based depression screening tools, as noted by Smarr et al. ${ }^{5}$ In addition, despite being one of the most commonly used paper and online depression screening tools, only one article reported psychometric properties for the PHQ-9 on the general population.

The CES-D and BDI-II have been validated and compared to the paper-based version of the tool. As described by
Buchanan, ${ }^{20}$ it cannot be taken for granted that the properties for the online and paper versions of an assessment tool are the same. However, contradictory to Buchanan, ${ }^{20}$ reliability properties comparison of results of the CES-D and the BDI-II online versus paper versions of these tools highlight very similar, if not the same, psychometric properties. However, when looking at the validity properties of the CES-D, it should be noted that the sensitivity is elevated and the specificity values are lowered significantly for the online version of the tool ${ }^{31}$ when compared to the paper-based version. ${ }^{10}$ These results could possibly be attributed to authors having selected a very specific target population when validating these screening tools, therefore highlighting 
a need for an online depression screening tool to be designed with a specific target population in mind.

The screening tools that were not among the commonly utilised depression screening tools showed relatively high psychometric properties; however, one should again be mindful of the fact that these tests were targeted to a very specific population and these results cannot be generalised to the general population. Finally, all of the screening tools utilised were based on the DSM-IV criteria and the articles included no discussion on the cross-cultural utility of the instruments used.

\section{Conclusion}

From the study results it is evident that a space exists for an online depression screening tool, specifically for the South African context. Given the more than adequate psychometric properties exhibited by the tools, it is recommended that the online screening tool should be adapted from the three most commonly used tools: PHQ-9, CES-D and BDI-II. The items in these tools will have to be assessed for cross-cultural applicability and linguistic appropriateness. Furthermore, the ethics of online screening for MDD will have to be further explored together with issues around the accuracy and privacy of individual outcomes on online MDD screening. Given the accessibility of such tools to a global population, there will be a need to clearly state the intended target population of the screening tool.

\section{Acknowledgement Competing interest}

The authors have declared that no competing interests exist.

\section{Author contributions}

T.H. was responsible for the write-up of the article under the supervision of S.L. S.L. was the supervisor of this project and provided guidelines for this review article. In addition, S.L. is credited with the conclusion points.

\section{Funding}

This work is based on the research supported wholly or in part by the National Research Foundation of South Africa (Grant Number:112948).

\section{Data availability statement}

Data sharing is not applicable to this article as no new data were created or analysed in this study.

\section{Disclaimer}

The views and opinions expressed in this article are those of the authors and do not necessarily reflect the official policy or position of any affiliated agency of the authors.

\section{References}

1. World Health Organisation. Depression: Fact sheet [homepage on the Internet] c2017 [cited 2017 July 06]. Available from: http://apps.who.int/iris/bitstream/ 10665/254610/1/WHO-MSD-MER-2017.2-eng.pdf
2. Ferrari AJ, Charlson FJ, Norman RE, et al. Burden of depressive disorders by country, sex, age, and year: Findings from the global burden of disease study 2010. PLOS sex, age, and year: Findings from the global burden of disease study 2010. PLOS
Med. 2013 Nov 5;10(11):e1001547. https://doi.org/10.1371/journal.pmed.1001547

3. Kerr LK, Kerr LD. Screening tools for depression in primary care. West J Med. 2001 Nov;175(5):349-52. https://doi.org/10.1136/ewjm.175.5.349

4. Ali G-C, Ryan G, Silva MJD. Validated screening tools for common mental disorders in low and middle income countries: A systematic review. PLOS ONE. 2016 Jun 16;11(6):e0156939. https://doi.org/10.1371/journal.pone.0156939

5. Smarr KL, Keefer AL. Measures of depression and depressive symptoms: Beck Depression Inventory-II (BDI-II), Center for Epidemiologic Studies Depression Scale (CES-D), Geriatric Depression Scale (GDS), Hospital Anxiety and Depression Scale (HADS), and Patient Health Questionnaire-9 (PHQ-9). Arthritis Care Res. 2011 Nov 1;63(S11):S454-S466. https://doi.org/10.1002/acr.20556

6. Nabbe P, Reste JYL, Guillou-Landreat M, et al. Which DSM validated tools for diagnosing depression are usable in primary care research? A systematic literature review. Eur Psychiatry. 2017 Jan 01;39:99-105. https://doi.org/10.1016/j.eurpsy. 2016.08.004

7. American Psychiatric Association. Diagnostic and statistical manual of mental disorders [Internet]. 5th ed. American Psychiatric Association [homepage on the Internet]. c2013 [cited 2019 Jan 03]. Available from: https://psychiatryonline.org/ doi/book/10.1176/appi.books.9780890425596

8. Gotlib IH, Hammen CL. Handbook of depression. 2nd ed. New York: Guilford Press; 2008, p. 721.

9. Crawford TA, Lipsedge M. Seeking help for psychological distress: The interface of Zulu traditional healing and Western biomedicine. Ment Health Relig Cult. 2004;7(2):131-148. https://doi.org/10.1080/13674670310001602463

10. Smit J, Myer L, Middelkoop K, et al. Mental health and sexual risk behaviours in a South African township: A community-based cross-sectional study. Public Health. 2006 Jun;120(6):534-542. https://doi.org/10.1016/j.puhe.2006.01.009

11. Kagee $A$, Nel A, Saal W. Factor structure of the Beck Depression Inventory-I among South Africans receiving antiretroviral therapy. AIDS Care. 2014 Feb 01;26(2):257-262. https://doi.org/10.1080/09540121.2013.802278

12. Baron EC, Davies T, Lund C. Validation of the 10-item Centre for Epidemiological Studies Depression Scale (CES-D-10) in Zulu, Xhosa and Afrikaans populations in South Africa. BMC Psychiatry. 2017 Jan 09;17(1):6. https://doi.org/10.1186/ s12888-016-1178-x

13. Makhubela M., Mashegoane S. Validation of the Beck Depression Inventory-II in South Africa: Factorial validity and longitudinal measurement invariance in university students. South Afr J Psychol. 2016 Jun 01;46(2):203-217. https://doi. org/10.1177/0081246315611016

14. Estabrook LS, Witt GE, Rainie H. Information searches that solve problems: How people use the internet, libraries, and government agencies when they need help [homepage on the Internet]. c2007 [cited 2018 Nov 13]. Available from: https:// www.pewinternet.org/2007/12/30/information-searches-that-solve-problems/

15. Morahan-Martin JM. How Internet users find, Evaluate, and use online health information: A cross-cultural review. Cyberpsychol Behav. 2004 Oct 01;7(5): 497-510. https://doi.org/10.1089/1094931042403082

16. Barney $\mathrm{L}$, Griffiths KM, Christensen H, Jorm AF. Exploring the nature of stigmatising beliefs about depression and help-seeking: Implications for reducing stigma. BMC Public Health. 2009 Feb 20;9(1):61. https://doi.org/10.1186/1471-2458-9-61

17. Africa SS. General Household Survey Statistics South Africa [homepage on the Internet]. c2016 [cited 2018 Nov 13]. Available from: http://www.statssa.gov. $\mathrm{za} / \mathrm{p}=9922$

18. The MHaPP Research Programme Consortium, Lund C, Kleintjes S, Kakuma R, Flisher AJ. Public sector mental health systems in South Africa: Inter-provincial comparisons and policy implications. Soc Psychiatry Psychiatr Epidemiol. 2010 Mar;45(3):393-404. https://doi.org/10.2196/jmir.3147

19. Renton $\mathrm{T}$, Tang $\mathrm{H}$, Ennis $\mathrm{N}$, et al. Web-based intervention programs for depression: A scoping review and evaluation. J Med Internet Res. 2014 Sep 23;16(9):e209. https://doi.org/10.2196/jmir.3147

20. Buchanan T. Internet-based questionnaire assessment: Appropriate use in clinical contexts. Cogn Behav Ther. 2003 Jan;32(3):100-119. https://doi.org/10.1080/ 16506070310000957

21. Grant MJ, Booth A. A typology of reviews: An analysis of 14 review types and associated methodologies: A typology of reviews, Maria J. Grant \& Andrew Booth. Health Inf Libr J. 2009 Jun;26(2):91-108. https://doi.org/10.1111/j.1471-1842. 2009.00848.x

22. Uman LS. Systematic reviews and meta-analyses. J Can Acad Child Adolesc Psychiatry. 2011 Feb;20(1):57-59.

23. Moher D, Liberati A, Tetzlaff J, Altman DG, Group TP. Preferred reporting items for systematic reviews and meta-analyses: The PRISMA statement. PLOS Med. 2009 Jul 21;6(7):e1000097. https://doi.org/10.1371/journal.pmed.1000097

24. Fowler, R.D. Landmarks in computer-assisted... - Google scholar [homepage on the Internet]. c1985. [cited 2019 Jan 03]. Available from: https://scholar.google. co.za/scholar?hl=en\&as_sdt $=0 \% 2 \mathrm{C} 5 \& \mathrm{q}=$ Fowler $\% 2 \mathrm{C}+\mathrm{R} .+\mathrm{D} .+\% 281985 \% 29 .+$ Land marks+in+computer-assisted+psychological+assessment.+Journal+of+Consulting +and+Clinical+Psychology $\% 2 C+53 \% 286 \% 29 \% 2 C+748$. \& btnG $=$

25. Elo S, Kyngäs $H$. The qualitative content analysis process. J Adv Nurs 2008;62(1):107-115. https://doi.org/10.1111/j.1365-2648.2007.04569.x

26. CASP. CASP checklists [homepage on the Internet]. CASP: Critical appraisal skills programme. [cited 2018 Nov 13]. Available from: https://casp-uk.net/casp-toolschecklists/

27. Harvey SB, Glozier N, Henderson M, et al. Depression and work performance: An ecological study using web-based screening. Occup Med Oxf Engl. 2011 May;61(3):209-211. https://doi.org/10.1016/j.jad.2007.07.003 
28. Krog MD, Nielsen MG, Le JV, Bro F, Christensen KS, Mygind A. Barriers and facilitators to using a web-based tool for diagnosis and monitoring of patients with depression: A qualitative study among Danish general practitioners. BMC with depression: A qualitative study among
Health Serv Res. 2018 Jun 27;18(1):503-503.

29. Spek V, Nykliček I, Cuijpers P, Pop V. Internet administration of the Edinburgh Depression Scale. J Affect Disord. 2008 Mar;106(3):301-305. https://doi.org/ 10.1016/j.jad.2007.07.003

30. Holländare F, Andersson G, Engström I. A comparison of psychometric properties between Internet and paper versions of two depression instruments (BDI-II and MADRS-S) administered to clinic patients. J Med Internet Res [serial online]. 2010 Dec 19 [cited 2018 Oct 31];12(5). Available from: https://www.ncbi.nlm.nih.gov/ pmc/articles/PMC3057311/

31. Herrero J, Meneses J. Short Web-based versions of the perceived stress (PSS) and Center for Epidemiological Studies-Depression (CESD) scales: A comparison to pencil and paper responses among Internet users. Comput Hum Behav. 2006 Sep;22(5):830-846. https://doi.org/10.1016/j.chb.2004.03.007

32. Williams A, Larocca R, Chang $T$, et al. Web-based depression screening and psychiatric consultation for college students: A feasibility and acceptability study. Int J Telemed Appl. 2014 Jan 1;2014:580786-580786. https://doi.org/10.1155/ 2014/580786

33. Jeong Youn S, Trinh N-H, Shyu I, et al. Using online social media, Facebook, in screening for major depressive disorder among college students. Int J Clin Health Psychol [serial online]. 2013 [cited 2018 Oct 31];13(1):74-80. Available from: http://www.redalyc.org/resumen.oa?id=33725623009

34. Lee J-S, Jeong B. Having mentors and campus social networks moderates the impact of worries and video gaming on depressive symptoms: A moderated mediation analysis. BMC Public Health. 2014 May 05;14:426-426. https://doi. org/10.1186/1471-2458-14-426

35. Du N, Yu K, Ye Y, Chen S. Validity study of patient health questionnaire-9 items for Internet screening in depression among Chinese university students. Asia-Pac Psychiatry Off J Pac Rim Coll Psychiatry. 2017 Sep;9(3):1-5. https://doi.org/ 10.1111/appy.12266

36. Leykin $Y$, Muñoz RF, Contreras $O$. Are consumers of Internet health information "cyberchondriacs"? Characteristics of 24,965 users of a depression screening site. Depress Anxiety 1091-4269. 2012 Jan;29(1):71-77. https://doi.org/10.1002/da.20848
37. Lup K, Trub L, Rosenthal L. Instagram \#instasad?: Exploring associations among instagram use, depressive symptoms, negative social comparison, and strangers followed. Cyberpsychology Behav Soc Netw. 2015 May;18(5):247-252. https:// followed. Cyberpsychology Behav
doi.org/10.1089/cyber.2014.0560

38. Donker T, van Straten A, Marks I, Cuijpers P. Brief self-rated screening for depression on the Internet. J Affect Disord. 2010 May;122(3):253-259. https:// doi.org/10.1016/j.jad.2009.07.013

39. Lin C-C, Bai Y-M, Liu C-Y, et al. Web-based tools can be used reliably to detect patients with major depressive disorder and subsyndromal depressive symptoms. BMC Psychiatry [serial online]. 2007 Dec [cited 2018 Sep 29];7(1):1. Available from: http://bmcpsychiatry.biomedcentral.com/articles/10.1186/1471 244X-7-12

40. Lin CC, Li YC, Bai YM, et al. The validity of an Internet-based self-assessment program for depression. AMIA Annu Symp Proc AMIA Symp. 2003;35(5): 911-911.

41. Gill S, Contreras O, Muñoz RF, Leykin Y. Participant retention in an automated online monthly depression rescreening program: Patterns and predictors. Internet Interv Appl Inf Technol Ment Behav Health. 2014 Mar;1(1):20-25. https://doi. org/10.1016/j.invent.2014.02.003

42. Moreno MA, Christakis DA, Egan KG, et al. A pilot evaluation of associations between displayed depression references on Facebook and self-reported depression using a clinical scale. J Behav Health Serv Res. 2012 Jul 01;39(3):295-304. https:// doi.org/10.1007/s11414-011-9258-7

43. Garlow SJ, Rosenberg J, Moore JD, et al. Depression, desperation, and suicidal ideation in college students: Results from the American Foundation for Suicide Prevention College Screening Project at Emory University. Depress Anxiety. 2008 Jun 1;25(6):482-488. https://doi.org/10.1002/da.20321

44. Moreno MA, Jelenchick L, Koff R, Eickhoff J. Depression and internet use among older adolescents: An experience sampling approach. Psychology. 2012 Sep;3(9A): 743-748. https://doi.org/10.4236/psych.2012.329112

45. Liu NH, Contreras O, Muñoz RF, Leykin Y. Assessing suicide attempts and depression among Chinese speakers over the Internet. Crisis. 2014;35(5):322-329. https://doi. org/10.1027/0227-5910/a000261 